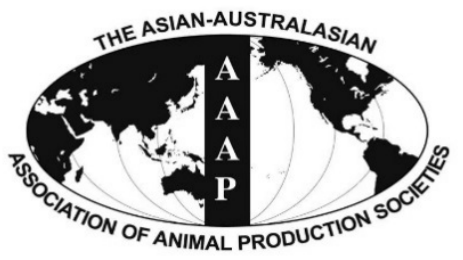

Open Access

Asian Australas. J. Anim. Sci.

Vol. 29 No. 5 : 624-630 May 2016

http://dx.doi.org/10.5713/ajas.15.0692

www.ajas.info

pISSN 1011-2367 elSSN 1976-5517

\title{
Haplogroup Classification of Korean Cattle Breeds Based on Sequence Variations of mtDNA Control Region
}

\author{
Jae-Hwan Kim, Seong-Su Lee, Seung Chang Kim, Seong-Bok Choi, Su-Hyun Kim¹, Chang Woo Lee², \\ Kyoung-Sub Jung ${ }^{3}$, Eun Sung Kim ${ }^{4}$, Young-Sun Choi ${ }^{5}$, Sung-Bok Kim ${ }^{6}$, Woo Hyun Kim ${ }^{7}$, and Chang-Yeon Cho* \\ Animal Genetic Resources Research Center, NIAS, RDA, Namwon 55717, Korea
}

\begin{abstract}
Many studies have reported the frequency and distribution of haplogroups among various cattle breeds for verification of their origins and genetic diversity. In this study, 318 complete sequences of the mtDNA control region from four Korean cattle breeds were used for haplogroup classification. 71 polymorphic sites and 66 haplotypes were found in these sequences. Consistent with the genetic patterns in previous reports, four haplogroups (T1, T2, T3, and T4) were identified in Korean cattle breeds. In addition, T1a, $\mathrm{T} 3 \mathrm{a}$, and T3b sub-haplogroups were classified. In the phylogenetic tree, each haplogroup formed an independent cluster. The frequencies of T3, T4, T1 (containing T1a), and T2 were $66 \%, 16 \%, 10 \%$, and $8 \%$, respectively. Especially, the T1 haplogroup contained only one haplotype and a sample. All four haplogroups were found in Chikso, Jeju black and Hanwoo. However, only the T3 and T4 haplogroups appeared in Heugu, and most Chikso populations showed a partial of four haplogroups. These results will be useful for stable conservation and efficient management of Korean cattle breeds. (Key Words: Haplogroup, mtDNA, Control Region, Korean Cattle Breed, Phylogenetic Tree)
\end{abstract}

\section{INTRODUCTION}

Cattle were introduced from North China to the Korean peninsula and Japan around A.D. 200 (Kim and Lee, 2000). Three cattle heads with brown, brindle or black coat colors,

* Corresponding Author: Chang-Yeon Cho. Tel: +82-63-6203520, Fax: +82-63-620-3590, E-mail: bloodtype@korea.kr

1 Gyeonggi Livestock and Veterinary Service, Suwon 16381, Korea.

${ }^{2}$ Gangwon Provincial Livestock Research Center, Hoengseong 25266, Korea.

3 Chungbuk Institute of Livestock and Veterinary Research, Cheongwon 28153, Korea.

${ }^{4}$ Jeonbuk Institute of Livestock and Veterinary Research, Gimje 54324, Korea.

${ }^{5}$ Jeonnam Agricultural Research and Extension Services, Gangjin 59213, Korea.

6 Chungnam Institute of Livestock Experiment Research, Cheongyang 33350, Korea.

7 Gyeongbuk Livestock Research Institute, Yeongju 36052, Korea.

Submitted Aug. 24, 2015; Revised Nov. 23, 2015; Accepted Jan. 5, 2016 are estimated to be the origin of the Korean cattle breeds (Na, 2008). At present, four cattle breeds, Hanwoo, Chikso, Heugu, and Jeju black, exist in Korea, and are classified based on their different coat colors and geographical distribution (Suh et al., 2014). These breeds have been documented in the Domestic Animal Diversity Information System (DAD-IS) of the United Nations Food and Agriculture Organization (FAO; http://dad.fao.org/). Because the three Korean native cattle breeds, except for Hanwoo, were recently recognized as possessing valuable genetic resources in Korea, molecular studies were performed on them using genetic markers for characteristic evaluation.

Various molecular genetic markers have been used to determine genetic diversity, molecular evolution and genetic relationship within and among cattle breeds (Horsburgh et al., 2013; Ludwig et al., 2013; San et al., 2014; Tu et al., 2014; Xin et al., 2014; Hristov et al., 2015). Of these, mitochondrial DNA (mtDNA) contains a maternal genetic pattern, and is a very useful marker for evaluating the origin and gene flow of modern cattle breeds. Especially, 
this marker has been used for the haplogroup classification of modern and extinct cattle (Gou et al., 2010; Dadi et al., 2012; Gravlund et al., 2012). At present, 6 haplogroups (T, T1, T2, T3, T4, and T5) have been reported among Europe, Africa, and Near East, and Asia cattle populations (Troy et al., 2001; Mannen et al., 2004; Achilli et al., 2008). The T3 haplogroup is distributed mainly in Europe and Asia, whereas T1 is found in Africa, T and T2 in the Near East, and T4 in the Northeast.

Korean cattle have been classified into the T2, T3, and T4 haplogroups, but mainly into the T3 haplogroup (Lai et al., 2006; Sasazaki et al., 2006; Jia et al., 2010). However, these studies did not classify the haplogroup at the breed level for Korean cattle. Therefore, the aims of the present study were to analyze the mtDNA control region sequence and to classify the mtDNA haplogroup of each Korean cattle breed.

\section{MATERIALS AND METHODS}

\section{Sample collection and DNA extraction}

A total of 288 animals (182 Chikso, 20 Heugu, and 86 Jeju black) were used in this study. Chikso samples were collected from 6 Management Institutes, Gyeonggi Livestock and Veterinary Service (GG), Gangwon Provincial Livestock Research Institute (GW), Chungbuk Institute of Livestock and Veterinary Research (CB), Jeonbuk Institute of Livestock and Veterinary Research (JB), Chungnam Institute of Livestock Experiment Research $(\mathrm{CN})$, and Jeonnam Agricultural Research and Extension Services (JN). Heugu and Jeju black samples were collected from $\mathrm{CB}$ and the Jeju Special Self-Governing Province Livestock Promotion (JJ), respectively. All samples were collected from each institute for detailed identification of haplogroups among the populations. The sequences for the Hanwoo breed were obtained from the GenBank database (http://www.ncbi.nlm.nih.gov/), distributed in 6 regions througthout Korea (Jeju, Jungeup, Cheongwon, Incheon, Youngju, and Yeoju) (AY337521-26, AY337529-41, AY337543-46). Genomic DNA was extracted from blood using the DNeasy Blood Kit (Qiagen, Hilden, Germany). The concentration of genomic DNA was measured using a model ND 1000 spectrometer (Thermo Scientific, Waltham, MA, USA).

\section{DNA amplification and sequencing}

Two primer sets were designed using the sequences for tRNA-Pro, the control region, and tRNA-Phe, according to the mtDNA genome sequences (GenBank accession no. V00654). The sequences of the two primer sets were as follows:

Set 1: 5'- ACCCCCAAAGCTGAAGTTCT -3' and 5'AGATGAGATGGCCCTGAAGA-3';
Set 2: 5'- GGGTCGCTATCCAATGAATT -3' and 5'GCATTTTCAGTGCCTTGCTT -3'.

Polymerase chain reaction (PCR) was carried out using $2.5 \mu \mathrm{L}$ of $10 \times$ reaction buffer, $0.2 \mathrm{mM}$ of dNTP, $1.5 \mathrm{mM}$ $\mathrm{MgCl}_{2}, 1.5$ units of Taq DNA polymerase (Takara, Tokyo, Japan), $10 \mathrm{mM}$ of each primer, and $10 \mathrm{ng}$ of genomic DNA in a final volume of $25 \mu \mathrm{L}$. The PCR amplification was performed using a PTC-200 (MJ Research, Waltham, MA, USA) under the following conditions: 35 cycles of $30 \mathrm{~s}$ at $94^{\circ} \mathrm{C}, 30 \mathrm{~s}$ at $63^{\circ} \mathrm{C}$, and $60 \mathrm{~s}$ at $72^{\circ} \mathrm{C}$. After purification of the PCR products using the QIAEX II Gel Extraction Kit (Qiagen, Germany), nucleotide sequencing was carried out by direct-sequencing with an ABI 3130xl Genetic Analyzer (PE Applied Biosystems, Foster City, CA, USA). The complete sequences of the complete control region were determined based on the complete sequences of the Bos taurus mtDNA genome sequence (Genbank accession no. V00654) as reported by Anderson et al. (1982). The determined sequences were deposited in the GenBank database (GenBank accession no. KR857524-74).

\section{Data analysis}

The sequences of the control region from four Korean cattle breeds were aligned in the CLUSTAL W program (Thompson et al., 1994) in the BioEdit software (Hall, 1999). Sites representing gaps in any of the aligned sequences were excluded from subsequent analyses. Identification of haplotypes was carried out using DNA sequence polymorphism version 5.1 (Librado and Rozas, 2009). Haplogroup classification was performed based on several previous reports (Troy et al., 2001; Achilli et al., 2008; Mannen et al., 2004). Genetic distances between haplotypes were estimated using the substitution model of Tamura and Nei (1993). The neighbor-joining (NJ) tree (Saitou and Nei, 1987) among haplotype sequences was reconstructed using the MEGA 5.05 package (Tamura et al., 2011).

\section{RESULTS AND DISCUSSSION}

In this study, 288 complete sequences of the mtDNA control region were determined. In additions, 30 Hanwoo sequences were obtained from the GenBank database. The entire length of the control region ranged from 908 to 912 bp, because two insertion/deletion mutation sites were found at nucleotide positions 216 to 221 and 352 to 363 in the complete control region sequences (GenBank accession no. V00654). These regions contained two poly-C tracts, and the mutations were excluded from subsequent analyses. 71 polymorphic sites were detected and 66 haplotypes were classified (Figure 1). Of these, 7 (H1, H4, H6-8, H10, H39) were major haplotypes that contained more than 10 sequences (Table 1). In addition, breed- and populationspecific sequences were found. 


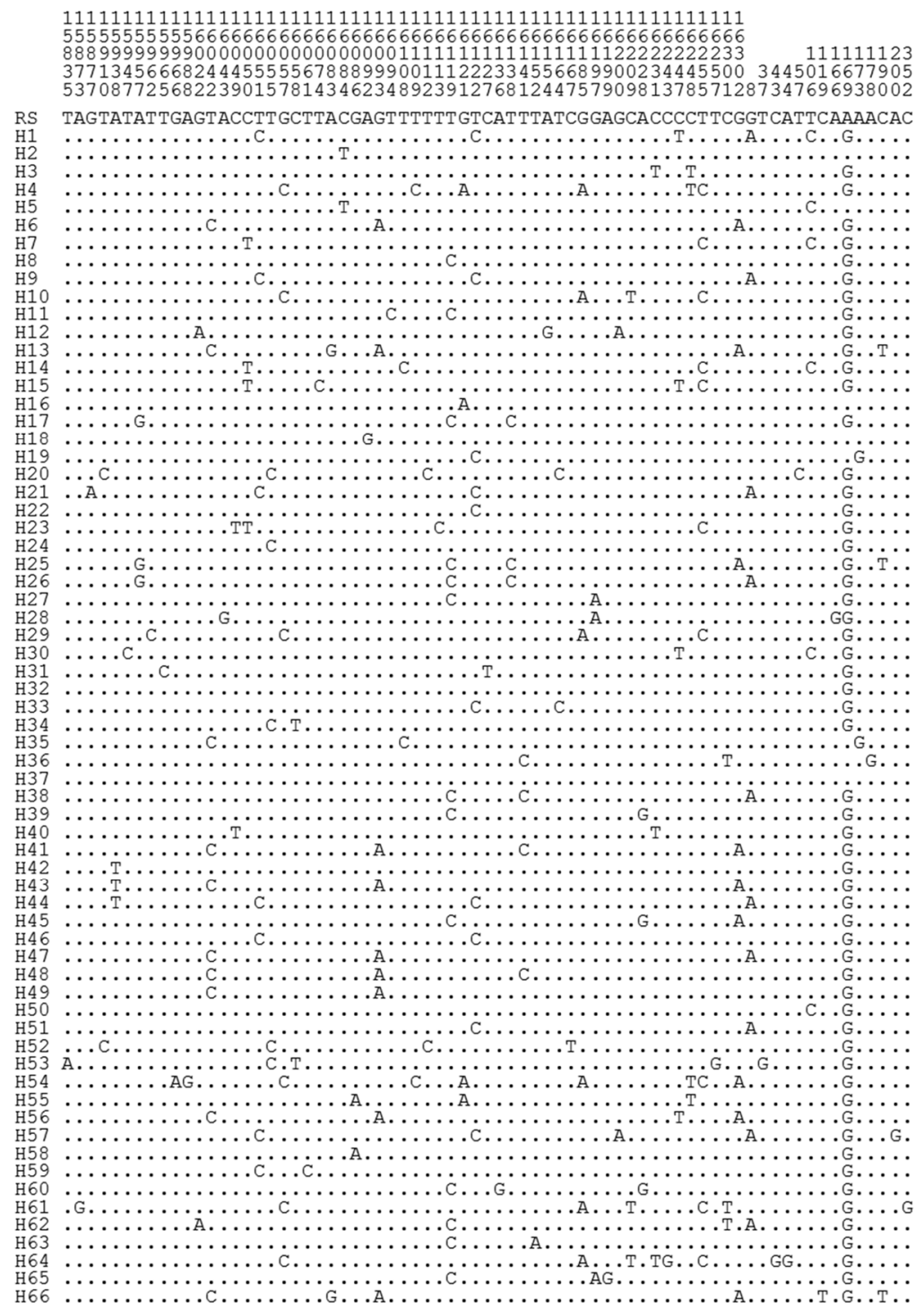

Figure 1. Sequence variations of 66 haplotypes in the mtDNA control region of four Korean cattle breeds. Mutations are scored relative to RS (GenBank accession no. V00654) of Anderson et al. (1982). Dots identify the RS sequence.

Table 1. i) Distribution of 66 haplotypes in four Korean cattle breeds based on sequence variations of the mtDNA control region

\begin{tabular}{|c|c|c|c|c|c|c|c|c|c|c|c|c|}
\hline \multirow{3}{*}{ Haplotypes } & \multicolumn{10}{|c|}{ Breeds } & \multirow{3}{*}{ Total } & \multirow{3}{*}{ Accession no. } \\
\hline & \multicolumn{7}{|c|}{ Chikso } & \multirow{2}{*}{ Heugu } & \multirow{2}{*}{ Jeju Black } & \multirow{2}{*}{ Hanwoo } & & \\
\hline & GW & $\mathrm{CB}$ & $\mathrm{JB}$ & GG & $\mathrm{CN}$ & $\mathrm{JN}$ & Sub-total & & & & & \\
\hline$\overline{\mathrm{H} 1}$ & 23 & & & & & 1 & 35 & & & & 35 & KR857525 \\
\hline $\mathrm{H} 2$ & 8 & & & & & & 8 & & & & 8 & KR857543 \\
\hline $\mathrm{H} 3$ & 4 & & & & & & 4 & & & & 4 & KR857529 \\
\hline $\mathrm{H} 4$ & 11 & & & & & & 11 & & & & 11 & KR857544 \\
\hline H5 & 3 & & & & & & 3 & & & & 3 & KR857535 \\
\hline H6 & 2 & 9 & & & & 7 & 18 & 2 & 16 & 3 & 39 & KR857553 \\
\hline $\mathrm{H} 7$ & & 9 & & & & & 9 & & 7 & 2 & 18 & KR857574 \\
\hline $\mathrm{H} 8$ & & 4 & & & 3 & & 7 & 14 & & 2 & 23 & KR857524 \\
\hline H9 & & 3 & & & & & 3 & & 4 & & 7 & KR857552 \\
\hline $\mathrm{H} 10$ & & 6 & & & & 1 & 7 & & 3 & 1 & 11 & KR857547 \\
\hline H11 & & 3 & & & & & 3 & & & & 3 & KR857530 \\
\hline H12 & & 2 & & & & & 2 & & & & 2 & KR857555 \\
\hline H13 & & 3 & & & & & 3 & & & & 3 & KR857540 \\
\hline H14 & & 1 & 3 & 1 & & & 5 & & & & 5 & KR857532 \\
\hline H15 & & & 7 & & & & 7 & & & & 7 & KR857527 \\
\hline
\end{tabular}


Table 1. ii) Distribution of 66 haplotypes in four Korean cattle breeds based on sequence variations of the mtDNA control region (Continued)

\begin{tabular}{|c|c|c|c|c|c|c|c|c|c|c|c|c|}
\hline \multirow{3}{*}{ Haplotypes } & \multicolumn{10}{|c|}{ Breeds } & \multirow{3}{*}{ Total } & \multirow{3}{*}{ Accession no. } \\
\hline & \multicolumn{7}{|c|}{ Chikso } & \multirow{2}{*}{ Heugu } & \multirow{2}{*}{ Jeju Black } & \multirow{2}{*}{ Hanwoo } & & \\
\hline & GW & $\mathrm{CB}$ & $\mathrm{JB}$ & GG & $\mathrm{CN}$ & $\mathrm{JN}$ & Sub-total & & & & & \\
\hline$\overline{\mathrm{H} 16}$ & & & 2 & & & & 2 & & & & 2 & KR857534 \\
\hline H17 & & & 7 & & 1 & & 8 & & & & 8 & KR857570 \\
\hline H18 & & & 3 & & & & 3 & & & & 3 & KR857541 \\
\hline H19 & & & 4 & & & 1 & 5 & & & & 5 & KR857536 \\
\hline $\mathrm{H} 20$ & & & 1 & & & & 1 & & & & 1 & KR857565 \\
\hline $\mathrm{H} 21$ & & & 7 & 1 & & & 8 & & & & 8 & KR857564 \\
\hline $\mathrm{H} 22$ & & & 3 & & & & 3 & & 5 & 1 & 9 & KR857572 \\
\hline $\mathrm{H} 23$ & & & 1 & & & & 1 & & & & 1 & KR857526 \\
\hline $\mathrm{H} 24$ & & & 1 & & & & 1 & & & & 1 & KR857537 \\
\hline $\mathrm{H} 25$ & & & 1 & & & & 1 & & & & 1 & KR857557 \\
\hline $\mathrm{H} 26$ & & & 1 & & & & 1 & & & & 1 & KR857561 \\
\hline $\mathrm{H} 27$ & & & 2 & 2 & & & 4 & & & & 4 & KR857531 \\
\hline $\mathrm{H} 28$ & & & & 1 & & & 1 & & & & 1 & KR857538 \\
\hline $\mathrm{H} 29$ & & & & 1 & & & 1 & & & & 1 & KR857568 \\
\hline $\mathrm{H} 30$ & & & & 1 & & & 1 & & & & 1 & KR857546 \\
\hline $\mathrm{H} 31$ & & & & 5 & & & 5 & & & & 5 & KR857528 \\
\hline $\mathrm{H} 32$ & & & & & 1 & 4 & 5 & & 3 & & 8 & KR857563 \\
\hline $\mathrm{H} 33$ & & & & & & 2 & 2 & & & & 2 & KR857542 \\
\hline $\mathrm{H} 34$ & & & & & & 1 & 1 & & & 2 & 3 & KR857550 \\
\hline $\mathrm{H} 35$ & & & & & & 1 & 1 & & & & 1 & KR857533 \\
\hline H36 & & & & & 2 & & 2 & & & & 2 & KR857539 \\
\hline $\mathrm{H} 37$ & & & & & & & & 4 & & & 4 & KR857554 \\
\hline $\mathrm{H} 38$ & & & & & & & & & 8 & & 8 & KR857545 \\
\hline H39 & & & & & & & & & 18 & 1 & 19 & KR857573 \\
\hline $\mathrm{H} 40$ & & & & & & & & & 9 & & 9 & KR857569 \\
\hline $\mathrm{H} 41$ & & & & & & & & & 3 & & 3 & KR857560 \\
\hline $\mathrm{H} 42$ & & & & & & & & & 1 & & 1 & KR857548 \\
\hline $\mathrm{H} 43$ & & & & & & & & & 1 & & 1 & KR857562 \\
\hline $\mathrm{H} 44$ & & & & & & & & & 1 & & 1 & KR857567 \\
\hline $\mathrm{H} 45$ & & & & & & & & & 1 & & 1 & KR857556 \\
\hline $\mathrm{H} 46$ & & & & & & & & & 1 & & 1 & KR857551 \\
\hline $\mathrm{H} 47$ & & & & & & & & & 1 & & 1 & KR857559 \\
\hline $\mathrm{H} 48$ & & & & & & & & & 1 & & 1 & KR857558 \\
\hline $\mathrm{H} 49$ & & & & & & & & & 1 & & 1 & KR857549 \\
\hline $\mathrm{H} 50$ & & & & & & & & & 1 & & 1 & KR857566 \\
\hline $\mathrm{H} 51$ & & & & & & & & & 1 & & 1 & KR857571 \\
\hline $\mathrm{H} 52$ & & & & & & & & & & 1 & 1 & AY337546 \\
\hline $\mathrm{H} 53$ & & & & & & & & & & 1 & 1 & AY337545 \\
\hline $\mathrm{H} 54$ & & & & & & & & & & 1 & 1 & AY337543 \\
\hline $\mathrm{H} 55$ & & & & & & & & & & 1 & 1 & AY337540 \\
\hline H56 & & & & & & & & & & 1 & 1 & AY337539 \\
\hline $\mathrm{H} 57$ & & & & & & & & & & 1 & 1 & AY337537 \\
\hline $\mathrm{H} 58$ & & & & & & & & & & 4 & 4 & AY337535 \\
\hline H59 & & & & & & & & & & 1 & 1 & AY337532 \\
\hline $\mathrm{H} 60$ & & & & & & & & & & 1 & 1 & AY337530 \\
\hline $\mathrm{H} 61$ & & & & & & & & & & 1 & 1 & AY337526 \\
\hline H62 & & & & & & & & & & 1 & 1 & AY337525 \\
\hline $\mathrm{H} 63$ & & & & & & & & & & 1 & 1 & AY337524 \\
\hline $\mathrm{H} 64$ & & & & & & & & & & 1 & 1 & AY337523 \\
\hline H65 & & & & & & & & & & 1 & 1 & AY337522 \\
\hline H66 & & & & & & & & & & 1 & 1 & AY337521 \\
\hline Total & 51 & 43 & 51 & 12 & 7 & 18 & 182 & 20 & 86 & 30 & 318 & \\
\hline
\end{tabular}

GW, Gangwon Provincial Livestock Research Center; CB, Chungbuk Institute of Livestock and Veterinary Research; JB, Jeonbuk Institute of Livestock and Veterinary Research; GG, Gyeonggi Livestock and Veterinary Service; CN, Chungnam Institute of Livestock and Veterinary Research; JN, Jeonnam Agricultural Research and Extension Services. 
Consistent with the genetic pattern reported by Mannen et al. (2004) and Jia et al. (2010), four haplogroups (T1, T2, T3, and T4) were identified in Korean cattle breeds (Figure 2). $\mathrm{T}$ and $\mathrm{T} 5$ haplogroups have been defined by a transition at positions 16255 and 163 in reference sequences (RS, V00654), respectively (Troy et al., 2001; Achilli et al., 2008; Jia et al., 2010). However, these haplogroups were absent in this study. The T4 haplogroup was differentiated from T3 by a transition at position 16042, 16093, and 16302 . Moreover, the T2 haplogroup was differentiatedd from $\mathrm{T}$ by a transition at position 16057 and a transversion at position 16185. T1, the African cattle specific haplogroup, was identified by a transition at position 16050 and 16113. In addition, T1a, a sub-haplogroup reported by Jia et al. (2010) and Achilli et al. (2008), differed in only one position, 16050 .

The phylogenetic tree was constructed using 66 haplotype sequences (Figure 3). This phylogenetic pattern was compared with the classified haplogroups. Each haplogroup formed an independent cluster. The T3 haplogroup was classified into $\mathrm{T} 3 \mathrm{a}$ and $\mathrm{T} 3 \mathrm{~b}$ subhaplogroups by previous reports (Achilli et al., 2008; Jia et al., 2010). In this study, T3a and T3b were differentiated by a mutation pattern at position 169. Partial haplotypes

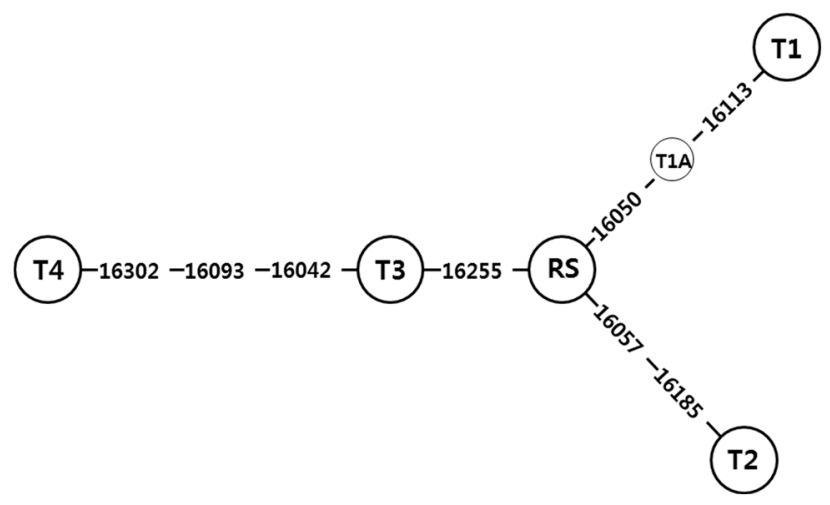

Figure 2. Genetic structure of haplogroups found in Korean cattle breeds. The numbers between haplogroups are variation sites that correspond to RS (GenBank accession no. V00654). T1a, a subhaplogroup of $\mathrm{T} 1$, is shown as smaller circle than the haplogroups.

contained in the T3b sub-haplogroups showed distinct mutation patterns in three positions $(16122,16055$, and 16119). The T4 haplogroup was separate from the $3 \mathrm{a}$ subhaplogroup, and this phylogenetical pattern agreed with previous reports (Achilli et al., 2008; Jia et al., 2010). The T1 haplogroup and the T1a sub-haplogroup were located together in an independent group.

Several studies have reported the frequency and

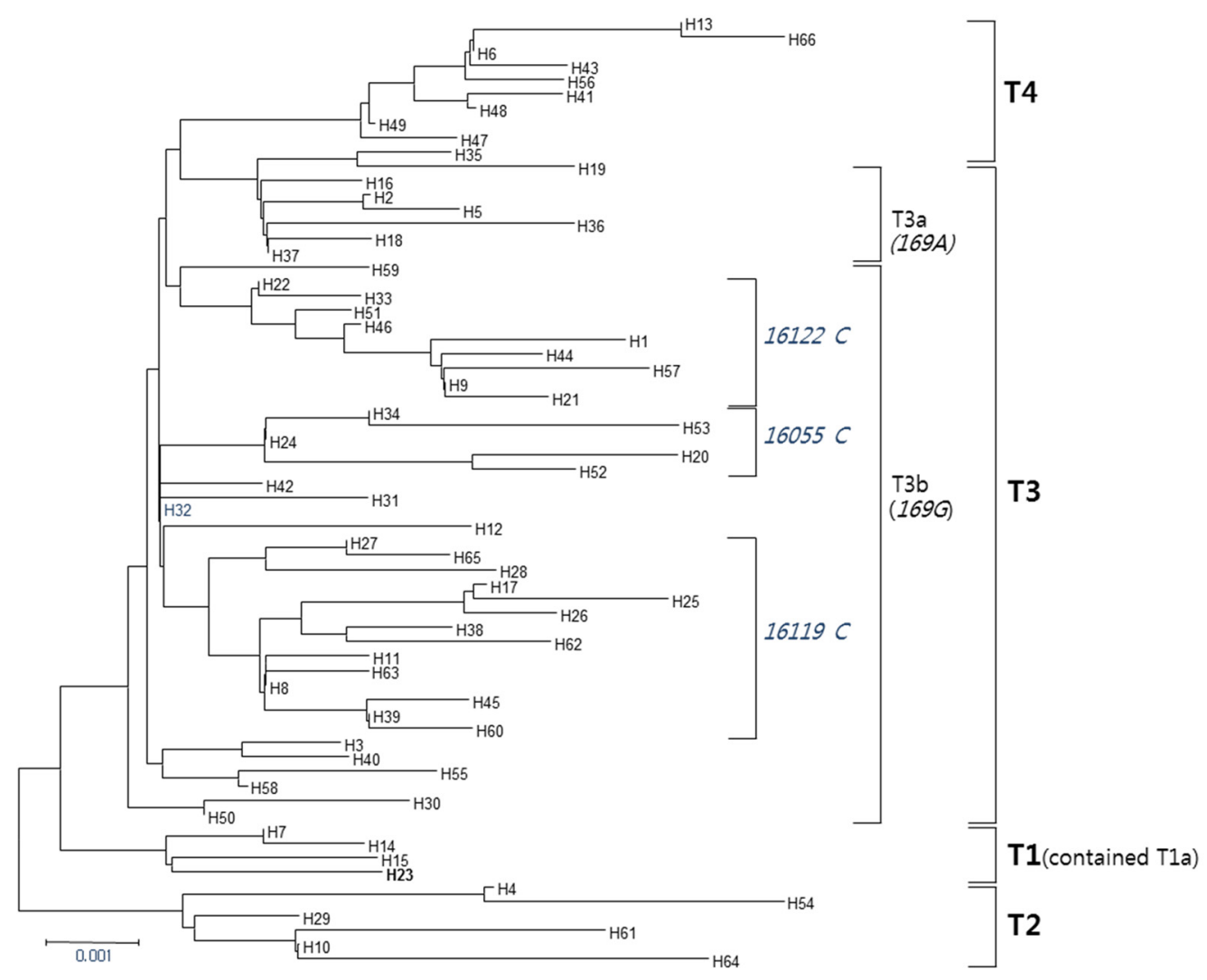

Figure 3. Neighbor-joining tree of 66 haplotypes in the mtDNA control region of four Korean cattle breeds. These haplotype were classified into four main lineages: T1 (containing T1a), T2, T3, and T4. T3a and T3b are sub-haplogroups of the T3 haplogroup according to published results (Jia et al., 2010). The italic numbers and letters in the brackets are variation sites and substituted nucleotides relative to RS (GenBank accession no. V00654), respectively. 
Table 2. Frequencies of haplogroups found in Korean cattle breeds/populations

\begin{tabular}{|c|c|c|c|c|c|c|c|}
\hline \multirow{2}{*}{\multicolumn{2}{|c|}{ Breeds (populations) }} & \multirow{3}{*}{$\begin{array}{c}\text { Sample sizes } \\
182\end{array}$} & \multicolumn{5}{|c|}{ Haplogroups } \\
\hline & & & \multirow{2}{*}{$\frac{\mathrm{T} 1}{1(0.01)}$} & \multirow{2}{*}{$\frac{\mathrm{T} 1 \mathrm{a}}{22(0.12)}$} & \multirow{2}{*}{$\frac{\mathrm{T} 2}{19(0.10)}$} & \multirow{2}{*}{$\begin{array}{c}\text { T3 } \\
119(0.65)\end{array}$} & \multirow{2}{*}{$\frac{\mathrm{T} 4}{22(0.12)}$} \\
\hline Chikso* & Sub-total & & & & & & \\
\hline & GW & 51 & & & 11 & 38 & 2 \\
\hline & $\mathrm{CB}$ & 43 & & 10 & 6 & 15 & 12 \\
\hline & JB & 51 & 1 & 10 & & 40 & \\
\hline & GG & 12 & & 1 & 1 & 10 & \\
\hline & $\mathrm{CN}$ & 7 & & & & 7 & \\
\hline & $\mathrm{JN}$ & 18 & & & 1 & 9 & 8 \\
\hline \multicolumn{2}{|l|}{ Heugu } & 20 & & & & $18(0.90)$ & $2(0.10)$ \\
\hline \multicolumn{2}{|l|}{ Jeju Black } & 86 & & $7(0.08)$ & $3(0.03)$ & $53(0.62)$ & $23(0.27)$ \\
\hline \multicolumn{2}{|l|}{ Hanwoo } & 30 & & $2(0.07)$ & $4(0.13)$ & $19(0.63)$ & $5(0.17)$ \\
\hline \multicolumn{2}{|l|}{ Total } & 318 & $1(>0.01)$ & $30(0.10)$ & $26(0.08)$ & $209(0.66)$ & $52(0.16)$ \\
\hline
\end{tabular}

GW, Gangwon Provincial Livestock Research Center; CB, Chungbuk Institute of Livestock and Veterinary Research; JB, Jeonbuk Institute of Livestock and Veterinary Research; GG, Gyeonggi Livestock and Veterinary Service; CN, Chungnam Institute of Livestock and Veterinary Research; JN, Jeonnam Agricultural Research and Extension Services.

distribution of haplogroups among various cattle breeds in East Asia (Mannen et al., 2004; Lai et al., 2006; Sasazaki et al., 2006; Jia et al., 2010). T3 was confirmed as the major haplogroup in Chinese cattle. On the other hand, the T4 haplogroup predominates (about 65\%) in Japanese cattle with approximately two fold higher frequency than T3. In Korean cattle, the frequency of the T3 haplogroup ranged from $69 \%$ to $83 \%$ and was the highest among the haplogroups. In this study, the haplotype distribution was confirmed among four Korean native cattle breeds (Table 2). The frequencies of T3, T4, T1 (containing T1a), and T2 were $66 \%, 16 \%, 10 \%$, and $8 \%$, respectively. The frequency of the T3 haplogroup was $66 \%$, which was lower than that of several previous reports (Mannen et al., 2004; Lai et al., 2006; Sasazaki et al., 2006; Jia et al., 2010). This difference may be explained by the number of samples and the haplogroups evaluated. Previous reports used a small number of samples (30 to 108). In addition, the $\mathrm{T} 1$ haplogroup and the T1a sub-haplogroup were found in only reports by Jia et al. (2010). Because we used over three times the number of samples, we estimate that our results more accurately reflect the haplogroup frequency in Korean cattle than previous reports.

T1 haplogroup contained only one haplotype and one sample (Table 2). Lei et al. (2006) investigated 231 animals from 20 Chinese native cattle breeds/populations. They reported that the T1 haplogroup was identified in only one animal from the Yanbian and Zaosheng breeds. Kim et al. $(2013 a, b)$ reported the phylogenetic relationship between Korean cattle breeds and these the two Chinese breeds. These results suggest that Korean cattle breeds and two Chinese breeds have similar maternal genetic patterns.

All four haplogroups were found in Chikso, Jeju black, and Hanwoo. However, only the T3 and T4 haplogroups appeared in Heugu. This breed is raised only one
Management Institute, and the population size is small. Hanwoo was different from the other breeds, with a higher frequency of the T2 haplogroup than the T1 haplogroup. In the Chikso breed, only the CB population contained all haplogroups. However, most Chikso populations showed a partial of four haplogroups. To maintain the genetic diversity of Chikso in the event of various environmental changes, exchange and use of genetic materials among populations is necessary.

In conclusion, we detected sequence variations in the mtDNA control region in Korean cattle breeds, and performed haplogroup distribution at the breed level. These results will be useful for stable conservation and efficient management of Korean cattle breeds. Besides, genetic characteristics based on mtDNA analysis might serve as a source for identification of the maternal origins of cattle, containing Korean cattle breeds.

\section{CONFLICT OF INTEREST}

We certify that there is no conflict of interest with any financial organization regarding the material discussed in the manuscript.

\section{ACKNOWLEDGMENTS}

This work was carried out with the support of "Cooperative Research Program for Agriculture Science \& Technology Development (Project No. PJ01029302)" Rural Development Administration, Republic of Korea.

\section{REFERENCES}

Achilli, A., A. Olivieri, M. Pellecchia, C. Uboldi, L. Colli, N. AlZahery, M. Accetturo, M. Pala, B. H. Kashani, U. A. Perego, V. 
Battaglia, S. Fornarino, J. Kalamati, M. Houshmand, R. Negrini, O. Semino, M. Richards, V. Macaulay, L. Ferretti, H. J. Bandelt, P. Ajmone-Marsan, and A. Torroni. 2008. Mitochondrial genomes of extinct aurochs survive in domestic cattle. Curr. Biol. 18:R157-R158.

Anderson, S., M. H. L. Debrujin, A. R. Coulson, I. C. Eperson, F. Sanger, and I. G. Young. 1982. Complete sequence of bovine mitochondrial DNA conserved features of the mammalian mitochondrial genome. J. Mol. Biol. 156:683-717.

Dadi, H., S. H. Lee, K. S. Jung, J. W. Choi, M. S. Ko, Y. J. Han, J. J. Kim, and K. S. Kim. 2012. Effect of population reduction on mtDNA diversity and demographic history of Korean cattle populations. Asian Australas. J. Anim. Sci. 25:1223-1228.

Gou, X., Y. Wang, S. Yang, W. Deng, and H. Mao. 2010. Genetic diversity and origin of Gayal and cattle in Yunnan revealed by mtDNA control region and SRY gene sequence variation. J. Anim. Breed. Genet. 127:154-160.

Gravlund, P., K. Aaris-Sørensen, M. Hofreiter, M. Meyer, J. P. Bollback, and N. Noe-Nygaard. 2012. Ancient DNA extracted from Danish aurochs (Bos primigenius): Genetic diversity and preservation. Ann. Anat. 194:103-111.

Hall, T. A. 1999. BioEdit: A user-friendly biological sequence alignment editor and analysis program for windows 95/98/NT. Nucleic Acids Symp. Ser. 41:95-98.

Horsburgh, K. A., S. Prost, A. Gosling, J. A. Stanton, C. Rand, and E. A. Matisoo-Smith. 2013. The genetic diversity of the Nguni breed of African cattle (Bos spp.): Complete mitochondrial genomes of haplogroup T1. PLoS One 8:e71956.

Hristov, P., D. Teofannova, B. Neov, and G. Radoslavov. 2015. Haplotype diversity in autochthonous Balkan cattle breeds. Anim. Genet. 46:92-94.

Jia, S., Y. Zhou, C. Lei, R. Yao, Z. Zhang, X. Fang, and H. Chen. 2010. A new insight into cattle's maternal origin in six Asian countries. J. Genet. Genomics 37:173-180.

Kim, J. B. and C. Lee. 2000. Historical look at the genetic improvement in Korean cattle - Review -. Asian Australas. J. Anim. Sci. 13:1467-1481.

Kim, J. H., M. J. Byun, M. J. Kim, S. W. Suh, Y. G. Ko, C. W. Lee, K. S. Jung, E. S. Kim, D. J. Yu, W. Y. Kim, and S. B. Choi. 2013a. mtDNA diversity and phylogenetic state of Korean cattle breed, Chikso. Asian Australas. J. Anim. Sci. 26:163-170.

Kim, J. H., M. J., Byun, M. J. Kim, S. W. Suh, Y. S. Kim, Y. G. Ko, S. W. Kim, K. S. Jung, D. H. Kim, and S. B. Choi. 2013b. Phylogenetic analysis of Korean black cattle Based on the Mitochondrial cytochrome $\mathrm{b}$ gene (in Korean). J. Life Sci. 23:24-30.

Lai, S. J., Y. P. Liu, Y. X. Liu, X. W. Li, and Y. G. Yao. 2006. Genetic diversity and origin of Chinese cattle revealed by mtDNA D-loop sequence variation. Mol. Phylogenet. Evol. $38: 146-154$

Lei, C. Z., H. Chen, H. C. Zhang, X. Cai, R. Y. Liu, L. Y. Luo, C. F. Wang, W. Zhang, Q. L. Ge, R. F. Zhang, X. Y. Lan, and W. B. Sun. 2006. Origin and phylogeographical structure of Chinese cattle. Anim. Genet. 37:579-582.
Librado, P. and J. Rozas. 2009. DnaSP v5: A software for comprehensive analysis of DNA polymorphism data. Bioinformatics 25:1451-1452.

Ludwig, A., L. Alderson, E. Fandrey, D. Liekfeldt, T. K. Soederlund, and K. Froelich. 2013. Tracing the genetic roots of the indigenous White Park cattle. Anim. Genet. 44:383-386.

Mannen, H., M. Kohno, Y. Nagata, S. Tsuji, D. G. Gradley, J. S. Yeo, D. Nyamsamba, Y. Zagdsuren, M. Yokohama, K. Nomura, and T. Amano. 2004. Independent mitochondrial origin and historical genetic differentiation in North Eastern Asian cattle. Mol. Phylogenet. Evol. 32:539-544.

Na, G. J. 2008. Characteristics of Korean native cattle (in Korean). Korea Animal Improvement Association Bulletin 1:42-52.

San, A., I. Martin-Burriel, C. Cons, M. Reta, A. Poblador, C. Rodellar, and P. Zaraqoza. 2014. Genetic diversity, structure and individual assignment of Casta Navarra cattle: a welldifferentiated fighting bull population. J. Anim. Breed. Genet. 131:11-18.

Saitou, N. and M. Nei. 1987. The neighbor-joining method: A new method for reconstructing phylogenetic trees. Mol. Biol. Evol. 4:406-425.

Sasazaki, S., S. Odahara, C. Hiura, F. Mukai, and H. Mannen. 2006. Mitochondrial DNA variation and genetic relationships in Japanese and Korean cattle. Asian Australas. J. Anim. Sci. 19:1394-1398.

Suh, S. W., Y. S. Kim, C. Y. Cho, M. J. Byun, S. B. Choi, Y. G. Ko, C. W. Lee, K. S. Jung, K. H. Bae, and J. H. Kim. 2014. Assessment of genetic diversity, relationships and structure among Korean native cattle breeds using microsatellite markers. Asian Australas. J. Anim. Sci. 27:1548-1553.

Tamura, K. and M. Nei. 1993. Estimation of the number of nucleotide substitutions in the control region of mitochondrial DNA in humans and chimpanzees. Mol. Biol. Evol. 10:512526.

Tamura, K., D. Peterson, N. Peterson, G. Stecher, M. Nei, and S. Kumar. 2011. MEGA5: Molecular evolutionary genetic analysis using maximum likelihood evolutionary distance, and maximum parsimony methods. Mol. Biol. Evol. 28:2731-2739.

Thompson, J. D., D. G. Higgins, and T. I. Gibson. 1994. CLUSTAL W: Improving the sensitivity of progressive multiple sequence alignment through sequence weighting, position-specific gap penalties and weight matrix choice. Nucl. Acids Res. 22:4673-4680.

Troy, C. S., D. E. MacHugh, J. F. Bailey, D. A. Maqee, R. T. Loffus, P. Cunningham, A. T. Chamberlain, B. C. Sykes, and D. G. Bradley. 2001. Genetic evidence for Near-Eastern origins of European cattle. Nature 410:1088-1091.

Tu, P. A., D. Y. Lin, G. F. Li, J. C. Huang, D. C. Wang, and P. H. Wang. 2014. Characterization of the genetic diversity and population structure for the yellow cattle in Taiwan based on microsatellite markers. Anim. Biotechnol. 25:234-249.

Xin, Y. P., L. S. Zan, Y. F. Liu, W. Q. Tian, H. B. Wang, G. Cheng, A. N. Li, and W. C. Yang. 2014. Genetic diversity of Y-short tandem repeats in Chinese native cattle breeds. Genet. Mol. Res. 13:9578-9587. 